COMUNICAÇÃO CIENTÍFICA

\title{
Ocorrência de Brevipalpus phoenicis (Geijskes) (Acari, Tenuipalpidae), Tetranychus urticae (Koch) (Acari, Tetranychidae) e Polyphagotarsonemus latus (Banks) (Acari, Tarsonemidae) sobre folhas de Ipomoea cairica (Linnaeus) Sweet (Solanales, Convolvulaceae) ${ }^{1}$
}

\author{
Ozana M. de A. Maia ${ }^{2,3} \&$ Zundir J. Buzzi ${ }^{2}$ \\ ${ }^{1}$ Contribuição número 1607 do Departamento de Zoologia, Universidade Federal do Paraná. \\ 2 Departamento de Zoologia, Universidade Federal do Paraná. Caixa Postal 19020, 81531-980 Curitiba, Paraná, Brasil. \\ E-mail: zbuzzi@ufpr.br \\ ${ }^{3}$ Bolsista do CNPq. E-mail: ozana_maia@yahoo.com.br
}

\begin{abstract}
Occurrence of Brevipalpus phoenicis (Geijskes) (Acari, Tenuipalpidae), Tetranychus urticae (Koch) (Acari, Tetranychidae) and Polyphagotarsonemus latus (Banks) (Acari, Tarsonemidae) on leaves of I. cairica (Linnaeus) Sweet (Solanales, Convolvulaceae). The first occurrence of three phytophagus mites on Ipomoea cairica, is reported. The species Brevipalpus phoenicis (Geijskes), Tetranychus urticae (Koch) and Polyphagotarsonemus latus (Banks) were caught on leaves of I. cairica, around Universidade Federal do Paraná, Curitiba, Paraná, Brazil, in January $20^{\text {th }}, 2005$.

KEY WORDS. Host plants; mites.
\end{abstract}

RESUMO. A ocorrência de três espécies acarinas fitófagas é relatada pela primeira vez sobre folhas de Ipomoea cairica. As espécies Brevipalpus phoenicis (Geijskes), Tetranychus urticae (Koch) e Polyphagotarsonemus latus (Banks), foram coletadas sobre folhas de I. cairica nas imediações da Universidade Federal do Paraná, Curitiba, Paraná, Brasil, em 20 de janeiro de 2005.

PALAVRAS-CHAVE. Ácaros; plantas hospedeiras.

Os ácaros Brevipalpus phoenicis (Geijskes, 1939), Tetranychus urticae (Koch, 1836) e Polyphagotarsonemus latus (Banks, 1904) são espécies cosmopolitas, sendo consideradas importantes pragas de várias culturas de interesse comercial.

Brevipalpus phoenicis ocorre em diversas plantas hospedeiras (Trindade \& Chiavegato 1994) e no Brasil, é associado à transmissão da leprose de citros, doença causada por vírus, considerada uma das mais graves doenças da laranjeira-doce, em nossas condições (Chiavegato et al. 1982, Oliveira 1988).

Já T. urticae ataca plantas como o tomate, feijão, soja, pêssego, figo, dentre outras de interesse econômico. É considerada a principal praga da cultura do morangueiro, podendo reduzir a produção de frutos em até $80 \%$, no ponto máximo de desenvolvimento da população, quando não controlado ou controlado de forma incorreta (Chiavegato \& Mischan 1981). Foi relatado como sendo uma das principais pragas da cultura do mamoeiro, juntamente com P. latus (SANCHEs et al. 2000), afetando seriamente seu desenvolvimento (VIEIRA et al. 2005).

Em 20 de janeiro de 2005, durante a realização de um levantamento das espécies que se alimentam de folhas da invaso- ra Ipomoea cairica (Linnaeus) Sweet (Solanales: Convolvulaceae), conduzido na Universidade Federal do Paraná, Curitiba, Estado do Paraná, foram coletados ovos e demais estágios ontogenéticos de B. phoenicis, T. urticae e P. latus.

Amostras de folhas foram coletadas e mantidas em refrigerador a aproximadamente $10{ }^{\circ} \mathrm{C}$, posteriormente, foram examinadas sob estereomicroscópio para coleta das espécies acarinas.

Para identificação, três exemplares de cada espécie foram montados em lâmina e lamínula, com meio de Hoyer (FLECHTMANN 1975). O material testemunho está depositado na Coleção de Ácaros do Departamento de Zoologia e Botânica (DZSJRP), Universidade Estadual Paulista, São José do Rio Preto, São Paulo, Brasil.

Plantas do gênero Ipomoea já foram relatadas como hospedeiras de insetos (MaiA \& Buzzi 2005) e de espécies de ácaros fitófagos (Gonzalez \& Viloria 1991, Childers et al. 2003).

A planta invasora I. cairica, conhecida comumente como corda-de-viola, é originária do Cairo e tem ampla distribuição no Brasil, ocorrendo desde a Amazônia até o Rio Grande do Sul (Kissmann 1991). Esta planta já foi relatada por Childers et al. 
(2003) como hospedeira das seguintes espécies acarinas: $B$. obovatus e $B$. californicus, passa agora a ser relatada também como hospedeira alternativa de três espécies de acarinas: $B$. phoenicis, T. urticae e P. latus.

Muitas vezes, plantas hospedeiras alternativas de ácaros fitófagos são mantidas dentro das culturas por abrigar ácaros predadores como Euseius citrifolius (Denmark \& Muma, 1970) e E. concordi (Chant, 1959) (Acari: Phytoseiidae), inimigos naturais de ácaros da família Tetranychidae em agroecossistemas (GERSOn et al. 2003, Moraes et al. 2004).

Entretanto deve-se ter em vista que os ácaros fitoseídeos possuem baixo consumo alimentar (MoRAEs 1991), nem sempre os ácaros fitófagos são seus alimentos preferidos, pois, algumas espécies se alimentam de polens, fungos, exsudados, insetos e secreções adocicadas (YuE \& Tsar 1996), e que alguns fitoseídeos preferem certos tipos de polens como alimento (McMurTry \& Croft 1997).

A constatação da presença de T. urticae e P. latus sobre $I$. cairica demonstra que esta deve ser inserida dentro dos programas de manejo integrado, por tratar-se de uma planta invasora, com alto poder vegetativo (KISSMANN 1991) e que pode estar mantendo e/ou incrementando as populações destas espécies dentro de culturas de interesse comercial.

Já a colonização por $B$. phoenicis, requer estudos posteriores que visem avaliar o potencial de I. cairica em hospedar o vírus da leprose dos citros, o que representa um risco para a citricultura, por constituir-se em focos de infecção, aumentando a probabilidade de contaminação do ácaro e, conseqüentemente, a disseminação dessa virose.

\section{AGRADECIMENTOS}

Ao Conselho Nacional de Desenvolvimento Científico e Tecnológico (CNPq), pelo suporte financeiro.

\section{REFERÊNCIAS BIBLIOGRÁFICAS}

Chiavegato, L.G. \& M.M. Mischan. 1981. Efeito do Tetranychus (T.) urticae (Koch, 1836) Boudreaux \& Dosse, 1963 (Acari, Tetranychidae) na produção do morangueiro (Fragaria sp.) cv. 'Campinas'. Científica, São Paulo, 9: 257-266.

Chiavegato, L.G.; M.M. Mischan \& M.A. Silva. 1982. Prejuízos e transmissibilidade de sintomas de leprose pelo ácaro Brevipalpus phoenicis (Geijskes, 1939) Sayed, 1946 (Acari, Tenuipalpidae) em citros. Científica, São Paulo, 10: 265-271.

Childers, C.C.; J.C.V. Rodrigues \& W.C. Welbourn. 2003. Host plants of Brevipalpus californicus. B. obovatus and B. phoenicis (Acari: Tenuipalpidae) and their potencial involvement in the spread of viral diseases vectored by these mites. Experimental and Applied Acarology, Netherlands, 30: 29-105.

Flechtmann, C.H.W. 1975. Elementos da Acarologia. São Paulo, Livraria Nobel, 344p.

Gerson, U.; R.L. Smiley \& R. Ochoa. 2003. Mites (Acari) in Biological Control. Boston, Blackwell Science, 539p.

GonZalez, M.Q. \& Z. Viloria. 1991. Tetranychus urticae Koch y Oligonychus bagdasariani Baker y Pritchard, (Acari: Tetranychidae) acaros fitofagos de importancia en vid (Vitis vinifera L.) en el estado Zulia-descripción taxonómica y daños. Revista de Agronomia, Luz, 8 (1): 1-14.

Kissmann, K.G. 1991. Plantas infestantes e nocivas. São Paulo, BASF, 608p.

MaIA, O.M.A. \& Z.J. Buzzi. 2005. Uma nova espécie de Charidotella Weise de Curitiba, Paraná, Brasil (Coleoptera, Chrysomelidae, Cassidinae). Revista Brasileira de Zoologia, Curitiba, 22 (3): 571-572.

McMurtry, J.A. \& B.A. Croft. 1997. Life-styles of phytoseiid mites and their roles in biological control. Annual Review of Entomology, Palo Alto, 42: 291-321.

Moraes, G.J. DE. 1991. Controle biológico de ácaros fitófagos. Informe Agropecuário, Belo Horizonte, 15 (167): 55-62.

Moraes, G.J. de; J.A. Mcmurtry; H.A. Denmark \& C.B. Campos. 2004. A revised catalog of the mite family Phytoseiidae. Zootaxa, Auckland, 434: 1-494.

Oliveira, C.A.L. DE. 1988. Ácaros: fator de redução da produtividade das plantas cítricas. In: A leprose dos citros no Brasil, p. 101-109. In: L.C. Donadio (ED.). Produtividade do citros. FUNEP, Jaboticabal, 207p.

Sanches, N.F.; A.S. Nascimento; D.S. Martins \& S.L.D. Marin. 2000. Pragas, p. 27-36. In: C.H.S.P. Ritzinger \& J.S. Souza (Eds). Mamão: fitossanidade. Brasília, Embrapa Comunicação para Transferência de Tecnologia, 91p.

Trindade, M.L.B. \& L.G. Chiavegato. 1994. Caracterização biológica dos ácaros Brevipalpus obovatus (Donnadieu, 1875), Brevipalpus californicus (Banks, 1904) e Brevipalpus phoenicis (Geijskes, 1939) (Acari: Tenuipalpidae) em variedades cítricas. Laranja, Cordeirópolis, 11: 227-240.

Vieira, M.R.; L.S.Correa; T.M.G. Castro; L.F.S. Silva \& M.S. VALVERDE. 2005. Efeito do cultivo do mamoeiro (Carica papaya L.) em ambientes protegidos sobre a ocorrência de ácaros fitófagos e moscas-brancas. Revista Brasileira de Fruticultura, Jaboticabal, 26 (3): 441-445.

Yue, B. \& J.H. Tsai. 1996. Development, survivorship and reproduction of Ambyseius largoensis (Acari: Phytoseiidae) on selected plant pollens and temperatures. Environmental Entomology, Lanham, 25 (2): 488-494.

Recebido em 10.I.2006; aceito em 21.VIII.2006. 